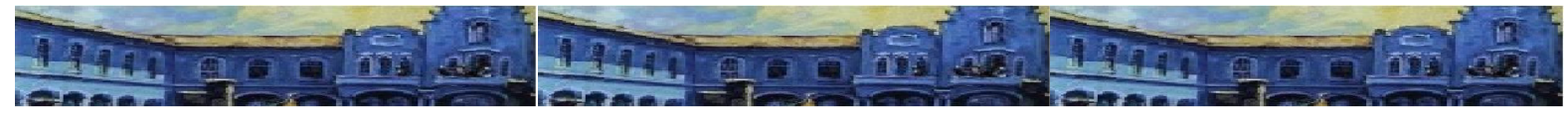

\title{
FEMINISMOS AYER Y HOY
}

\author{
Sylvia Marcos ${ }^{2}$
}

\section{RESUMEN}

En México, el movimiento de mujeres emerge con las características sociales propias de un país producto de la invasión y dominación de las culturas indígenas por La conquista y colonización española. Es en este contexto que se inscribe la vida de las mujeres mexicanas. A lo largo de la historia, nuestro país no ha dejado de buscar la integración de estos orígenes en una nación mexicana que reconozca esta doble herencia. El movimiento de las mujeres o movimiento feminista nace y se desarrolla en este entorno inherentemente injusto, difícil, pero también combativo. Desde sus inicios, ha luchado abiertamente contra la opresiva moral católica que ha afectado la vida de las mujeres y su relación con los varones, tanto en la sexualidad, la familia y el trabajo, como en lo social y político. Reconocemos que la presencia de mujeres indígenas en las filas del EZLN contribuyó a legitimar la participación política e insurgente de las mujeres, no sólo em México, sino en el mundo. Este movimento imprimen una calidad a muchas organizaciones hacia los esfuerzos en contra del sistema capitalista, a deslindarse del feminismo que solo ve la subordinación a los varones y deja de lado las múltiples subordinaciones cotidianas y rastreras que nos impone el capitalismo bárbaro y salvaje que destruye no sólo al planeta, sino toda posibilidad de supervivencia humana en armonía y justicia.

Palabras-clave: Feminismo anticapitalista; Mujeres indígenas; Historia feminista.

\section{FEMINISMOS ONTEM E HOJE}

\section{RESUMO}

No México, o movimento das mulheres surge com características sociais típicas de um país resultado da invasão e dominação de culturas indígenas pela conquista e colonização espanhola. É nesse contexto que se inscreve a vida das mulheres mexicanas. Ao longo da história, nosso país não parou de buscar a integração dessas origens em uma nação mexicana que reconheça essa dupla herança. 0 movimento de mulheres ou movimento feminista nasce e se desenvolve neste ambiente inerentemente injusto, difícil, mas combativo. Desde o início, este movimento lutou abertamente contra a moral católica opressiva que tem afetado a vida das mulheres e suas relações com homens, tanto no que diz respeito à sexualidade, à família e ao trabalho, tanto nas relações sociais quanto políticas. Reconhecemos que a presença de mulheres indígenas nas fileiras do EZLN ajudou a legitimar sua participação política insurgente, não só no México, mas em todo o mundo. Este movimento qualifica muitas organizações para o esforço contra o sistema capitalista ao distanciar-se do feminismo que só vê a subordinação aos homens e ignora as outras subordinações diárias e

\footnotetext{
${ }^{1}$ Feminismos ayer y hoy foi publicado originalmente dentro da obra "Conceptos fundamentales de nuestro tempo", sob a coordenação de Pablo Gonzáles Casanova, ISS Universidade Autônoma do México (UNAM), março de 2010, p. 1-20. O artigo foi gentilmente cedido pela autora.

${ }^{2}$ Sylvia Marcos é pós-doutora, professora visitante da Faculdade de Estudos das Religiões da Pós-Graduação da Universidade de Claremont/California (EUA) e professora da Universidade Autônoma do México (UNAM). Email: <smarcost@gmail.com>.
} 
rasteiras que nos foram impostas pelo capitalismo bárbaro e selvagem que destrói não só o planeta, mas a possibilidade de sobrevivência humana em harmonia e justiça.

Palavras-chave: Feminismo anticapitalista; Mulheres indígenas; História feminista.

\title{
FEMINISM YESTERDAY AND TODAY
}

\begin{abstract}
The womens' movement arises with the tipical social characteristics of a country which resulted of a invasion and domination of indian cultures by Spanish conquest and colonization. In this contexto, the Mexican womens' life is incribed. Along the history, our country did not stop to search the integration of these origins in a Mexican nation who recognizes this double heritage. The womens' movement or the feminist movement appears and it is developed in this inherently unfair, hard, but combative environment. Since the start, this movement has openly fighthen against the oppressive catholic moral which has affected the womens' life and their relationship with men, both regarding to the sexuality, family and work, and in social and political relations. We have recognized that the presence of Indigenous women in the rank of EZLN has helped to legitimize their participation in the insurgent policy, not only in Mexico, but all over the world. This movement qualifies several organizations to the effort against the capitalis system when distance itself from the feminism which sees only subordination to the men and ignores other daily subordinations which were inposed by the barbaric and savage capitalism that destroys not only the planet, but the human survival in harmony and justice.
\end{abstract}

Key-words: Anticapitalist feminism; Indigenous women; Feminist History.

\section{Feminismos ayer y hoy}

Debido a la conmoción cultural que generó su exigencia de participación política y cívica desde finales del siglo XIX hasta mediados de siglo XX, las mujeres se volvieron objeto de estudio para las ciencias sociales, la historiografía y otras disciplinas. Desde entonces, han militado atrevidamente, incursionando creativamente en formas inusitadas de activismo y en la lucha por el reconocimiento de sus derechos en todos los campos. Han abierto nuevos horizontes en la academia, la investigación, la cultura, la literatura. Las mujeres se han dado a la tarea de recuperar, descubrir, develar y exponer historias que el androcentrismo dominante, tanto en las relaciones sociales cuanto en los campos científicos y académicos, había invisibilizado por siglos.

En México, el movimiento de mujeres emerge con las características sociales propias de un país producto de la invasión y dominación de las culturas indígenas por la conquista y colonización española. Es en este contexto que se inscribe la vida de las mujeres mexicanas. A lo largo de la historia, nuestro país no ha dejado de buscar la integración de 
estos orígenes en una nación mexicana que reconozca esta doble herencia. El movimiento de las mujeres o movimiento feminista nace $y$ se desenvuelve en este entorno inherentemente injusto, difícil, pero también combativo. Desde sus inicios, ha luchado abiertamente contra la opresiva doble moral católica que ha afectado la vida de las mujeres y su relación con los varones, tanto en la sexualidad, la familia y el trabajo, como en lo social y político.

Pero la presencia indígena se mantuvo marginada e invisibilizada tanto en el conjunto de la sociedad cuanto dentro del mismo movimiento de las mujeres. El capitalismo, especialmente en su vertiente neoliberal que absolutiza el libre mercado y requiere la explotación voraz de la naturaleza sin controles ni regulaciones constituye otro frente en que las demandas feministas deben de enmarcarse. Hasta el levantamento zapatista en enero de 1994, las demandas referentes a derechos de los pueblos indios o "grupos étnicos" y las críticas a su situación de explotación y marginación estuvieron virtualmente ausentes de los movimientos sociales mexicanos, por lo que la discriminación y el racismo han sido integrados al contexto socio-cultural y económico del país. Esta actitud prevaleció demasiado tiempo inclusive en las agrupaciones que reivindicaban la justicia social. Según esa actitud, la pobreza y el atraso se relacionarían con los rasgos fenotípicos y culturales de los sesenta y dos grupos indígenas.

\section{Genealogía del feminismo mexicano}

A principios de los años setenta, el emergente movimiento feminista de la "segunda ola" (ROWBOTHAM, 1980) dedicó sus esfuerzos a reclamar los derechos de las mujeres. Al principio, el feminismo mexicano tomó la mayoría de sus demandas prestadas de aquéllas de movimientos feministas del Norte geopolítico. Este feminismo desmitificó eficazmente la doble moral patriarcal en relación a la sexualidad y al aborto, y desenmascaró los estereotipos femeninos que pretendían hacer depender la identidad de una mujer exclusivamente del tener un marido y de ser madre. Los pequeños grupos de autoconciencia permitieron que nuevas demandas fueran expresadas y articuladas.

Como consecuencia, muchas mujeres empezaron a involucrarse en áreas como la literatura, el teatro el cine, y en actividades políticas donde participaron en partidos, 
generalmente de izquierda. El término "machismo-leninismo" fue acuñado entonces por aquéllas que participaban en grupos políticos de lo que entonces se denominaba el marxismo-leninismo. En estas luchas, su postura feminista implicaba desenmascarar el patriarcalismo soterrado e implícito presente aun en las propuestas de justicia social. En esta época, las feministas eran mayoritariamente mujeres de clase media. Así, el feminismo mexicano tiene desde sus inicios un doble rostro: por un lado, cuestiona los roles de su misión y dependencia asignados a las mujeres por ideologías patriarcales en la sociedad en su conjunto y por otro lado, cuestiona también, al interior de las organizaciones de izquierda, la reproducción de estas normas hasta entre aquéllos que se proponían luchar en contra de la explotación y opresión de los desposeídos por el capitalismo. Es en el dilema inicial de esta militancia que se ha gestado el movimento feminista de izquierda mexicano, "[un] movimiento feminista con la ventaja comparativa de un historial descentralizado y horizontal" (LEÓN, 2005, p. 5) que desde sus inicios (aun si sólo potencialmente) nace bajo el signo de la pluralidad, obligado, por decirlo así, a recoger posturas múltiples, diversas y algunas veces contradictorias en sus demandas.

En 1976, los diversos grupos feministas comenzaron a trabajar coordinadamente. Se formó la Coalición de Mujeres Feministas (MARCOS, 2000). Esto contribuyó a que el movimiento feminista empezara a ser considerado como una fuerza social. Sus diversidades lograron unificarse en tres demandas principales: 1) maternidad voluntaria, que incluía la educación sexual, el uso de anticonceptivos, y la demanda a un abortolibre y gratuito; 2) la lucha contra la violencia sexual, en particular toda violencia hacia; 4) las mujeres; 3) los derechos a las preferencias sexuales "otras" de las lesbianas y de los homosexuales. Como resultado de estas demandas, el primer proyecto legislativo sobre maternidad voluntaria fue elaborado y presentado en 1976. Un año después, fue creado el primer centro de asistencia para las víctimas de violación y de violencia sexual.

Durante estos años, aparecieron las primeras publicaciones feministas, Fem y La Revuelta. Será hasta el 1980 que comenzaron a producirse programas radiofónicos con un enfoque feminista. Cabe resaltar que este movimiento, que comenzó y creció sobretodo en la ciudad de México, se extendió ese mismo año a otros estados de la República. El Estado de Morelos fue pionero al respecto, ya que desde 1972 se había formado el primer Centro de Documentación sobre las mujeres en CIDAL - luego CIDHAL - y que la actividad feminista fue 
muy precursora en este Estado en muchos otros aspectos. En 1979 se funda el Frente Nacional por la Liberación y los Derechos de las mujeres - o FNALIDM - en el que, por primera vez en la historia del feminismo mexicano, mujeres de muy diversos sectores sociales, diversas perspectivas e intereses, no necesariamente feministas, se unieron. Entre ellas se encontraban por ejemplo integrantes de la Unión Nacional de Mujeres ligadas a la Federación Internacional Democrática de Mujeres; activistas de los partidos de izquierda; mujeres de elite del partido en el poder, el Partido Revolucionario Institucional - o PRI; integrantes de grupos lésbicos; comités de madres de desaparecidos encabezados por Rosario Ibarra de Piedra; prisioneros políticos; sindicalistas y obreras, mujeres organizadas del movimento urbano popular y campesinas. Esta coalición de supervivencia precaria presentó un reto para las propuestas del movimiento inicial de grupos de autoconciencia que se habían instalado principalmente en la micro-política de sus cuerpos y su sexualidad, o en la creación literaria/intelectual como en abrir espacios de igualdad entre varones y mujeres en ámbitos sociales, sin cuestionar las estructuras económicas en las que estaban inscritas ni la marginación y pobreza que esas generaban. El principal objetivo del FNALIDM era crear una fuerza política fusionada implícitamente por la universalidade de la opresión de las mujeres. No fue hasta años después que el tema de las diferencias entre mujeres de diferentes extractos sociales, culturales, educativos, económicos y étnicos empezó a elaborarse y tomarse en cuenta. Esto es lo que permitió la construcción de nuevos feminismos.

Esta colaboración tuvo su punto más álgido durante los años ochenta. Las mujeres de los sectores urbano-populares, las obreras y sindicalistas, las campesinas e indígenas y las migrantes rurales que vivían en condiciones de pobreza comenzaron a conjuntar sus demandas específicas con aquéllas de las mujeres del movimiento feminista, académicas y políticas. En esos años, un movimiento amplio de mujeres comenzó a configurarse con todas sus diversidades, tensiones internas, avances y retrocesos. Esta amplitud y heterogeneidad introduce en el proyecto, además del feminismo, otros discursos y prácticas, maneras diversas de entender la condición de subordinación de las mujeres y, por consiguiente, complicaciones para la definición de las estratégias requeridas para lograr propósitos cada vez mas diferenciados (LAMUS, 2008). 
Aquellos años estuvieron marcados por negociaciones difíciles, toda vez que las prioridades de las mujeres que vivían en condiciones precarias parecían no tener coincidencias con las que eran propias de las mujeres de clase media. Como muchas de éstas últimas eran de filiación de izquierda, gradualmente lograron compartir las prioridades de las mujeres explotadas y desposeídas. Al mismo tiempo también, se filtraron las demandas del feminismo en contra del machismo - una regla patriarcal que implica que los hombres tienen todos los derechos y las mujeres todas las obligaciones - entre las mujeres campesinas, las sindicalistas, las del movimiento urbano-popular quienes incluyeron estos debates dentro de sus agendas políticas. A partir de entonces, el reto principal del movimiento feminista ha sido como conjuntar los derechos de los desposeídos con los derechos de las mujeres como tales.

Los grupos feministas pueden ubicarse dentro de un continuum entre dos polos. El primer polo da prioridad a los derechos de las mujeres, independientemente de la clase y perspectivas culturales o étnicas. El otro polo considera los derechos de los desposeídos y los reivindica si necesario al margen de los derechos de las mujeres. Este espectro incluye todo los puntos intermedios en que se dan yuxtaposiciones, superposiciones y paralelismos entre estas dos posturas extremas que, además, raras veces se presentan en forma esquemática en la realidad.

\section{El feminismo como teoría social crítica}

El concepto de género, que aparece sustituyendo y ampliando el de la "situación de las mujeres" o de los "roles y estereotipos sociales" (MARCOS, 1977) a principios de los años noventa, tiempos de la creación del Programa Universitario de Estudios de Genero, PUEG, de la UNAM, confirma la evidencia de relaciones de poder y desigualdade estructural entre los sexos, cuyas manifestaciones alcanzan todas las esferas de la vida social y privada, a tal punto que su erradicación es parte de los compromisos éticos impostergables, no sólo de las sociedades, sino sobre todo de los movimentos comprometidos con la articulación de propuestas alternativas al despojo de las mayorías avalado por las sociedades "modernas" neoliberales (LAMUS, 2008). 
En este nuevo dominio, se empezó a teorizar sobre las "relaciones de género" en sociedades patriarcales. Estas son también relaciones de poder y se refieren a sometimientos, subordinaciones, desequilibrios entre hombres y mujeres. Es importante conocer las formas en que la construcción social y cultura de las relaciones de género permite, a través de la socialización, que los mandatos sociales sean internalizados y considerados "naturales". Hablo de lo que he llamado la "naturalización" del género (MARCOS, 2000). Así, en el ámbito académico, el concepto de género en tanto categoría analítica sirvió de base para la subsiguiente teorización. La delimitación de este útil analítico permitió estudiar las diferencias socioculturales atribuibles a la diferencia entre hombres y mujeres y volver esta extensiva a la comprensión de otras categorías sociales que marcan diferencias y jerarquizan las relaciones de los seres sociales tales como la raza, la clase, la etnia, la preferencia sexual. Así se empezó a elaborar una nueva perspectiva teórica en el feminismo: la teoría de las intersecciones (COLLINS, 1998; LUGONES, 2009). Se habla así de una "matriz de dominación" en la cual se encuentran interconectadas todas esas otras formas de exclusión y despojo. Se requiere una configuración feminista en la cual el género sea una variable teórica más, pero que no debe ser separada de otros ejes de opresión. Los esfuerzos teóricos y las propuestas prácticas y organizativas en torno las intersecciones complican, pluralizan y particularizan el significado del concepto "mujer". Este es el desafío que enfrentan hoy en día las investigadoras y activistas de izquierda que quieren forjar, proponer y construir articulaciones estratégicas por encima de las diferencias teóricas y políticas fundadas en diferencias de raza, etnia, clase y preferencia sexual, para desafiar las definiciones mismas del discurso intelectual, académico y hegemónico sobre el género.

Este “quiebre epistémico" (LAMUS, 2009, p. 114), que abre a una nueva comprensión del feminismo, se inicia con los planteamientos del feminismo cultural norteamericano com sus llamados a la diversidad, en rechazo al feminismo de los setentas al que considera monolítico, elitista y poco abierto a la pluralidad racial y económica. Las analistas y activistas denunciaron el "etnocentrismo clasista" de la teoría feminista dominante (ALARCÓN, 1990), exigiendo reconocimiento, poder y respeto para las perspectivas emanadas desde las situaciones sociales y económicas desfavorecidas de las mujeres "de color" e instaladas en el imperio (ANZALDUA, 1987; LORDE, 1984; TRINH, 1989). 


\section{Los movimientos de mujeres indígenas: feminismos abajo y a la izquierda}

Rescatar la tradición intelectual feminista, desde "abajo y a la izquierda", implica mucho más que elaborar un análisis feminista utilizando las referencias y critérios epistemológicos establecidos. Se requiere de una epistemología feminista descolonizada.

Es crucial reinventar nuevas herramientas conceptuales que den cuenta de las formas específicas que cobra la opresión de género en contextos como el de las indígenas Mayas, Kichuas, Aymaras, Mapuches, por ejemplo. Además, cabe plantear varias preguntas: ¿Qué puede aportar el saber producido por un movimiento indígena alfeminismo en tanto que teoría social crítica? ¿De qué manera el vínculo entre identidad/fusión comunitaria e identidad de género marca derroteros sobre un movimiento indígena? Esas preguntas invitan a poner a debate el lugar otorgado al género en las agendas políticas de los movimientos sociales que reivindican sus raigambres ancestrales.

Conjuntamente a la redacción de los documentos de la Primera Cumbre de Mujeres Indígenas de América (Memoria, 2003), las mujeres indígenas organizadas, produjeron colectivamente un documento intitulado "Género desde la visión de las mujeresindígenas". El análisis de este documento - como de otro intitulado "El empoderamiento para garantizar la plena, activa y propositiva participación de las mujeres indígenas" - da pautas para rastrear raíces filosóficas culturales ancestrales a la vez que para revisar las re-conceptualizaciones y resignificaciones de ciertos términos feministas que las mujeres indígenas van haciendo. Es un proceso de intercambio pero sobre todo de apropiaciones filosóficas multidimensionales (MARCOS, 2009 b).

La afirmación arrogante de la superioridad de unas formas de conocer sobre otras - y ya no sólo de una raza sobre otra, prevaleciente desde la conquista y la colonización de México - está implícita en el "borramiento epistémico y político" (MIGNOLO, 2003) de las formas locales de aprehender el mundo que perviven en las cosmo visiones maya em particular y de las Américas en general. En contraposición a estas pretensiones hegemónicas, el movimiento social y político más relevante de nuestro tiempo, el zapatismo, ha construido sus propuestas políticas, sus formas de autonomía y autogobierno, sus objetivos de lucha sobre una re-creación de saberes ancestrales mesoamericanos. Como lo 
afirmara José Saramago en el acto final de una reunión com la comandancia del EZLN, "su propuesta política es otra" (MIGNOLO, 2003).

No es de extrañar que, justamente para el zapatismo, la inclusión de las mujeres y su participación equitativa en los puestos de autoridad, su capacidad de assumir responsabilidades en sus comunidades a la par con los varones y su exigencia de um trato digno y respetuoso hacia ellas sean la propuesta política zapatista, en el sentido de que no es "una más" entre prioridades organizadas jerárquicamente. "No sostenemos que la lucha por la tierra es prioritaria sobre la lucha de género" como lo señalara el Subcomandante Marcos (MARCOS, Subcomandante, 2009, p. 230) Planeta tierra y movimientos antisitémicos Chiapas: CIDECI: 230).

Desde una perspectiva social crítica, lo que emerge del zapatismo en sus prácticas políticas es un principio según el cual todos los énfasis son necesarios e imbricados unos en otros, se interconectan y son interdependientes. No se organizan en pirâmides jerárquicas ni tampoco en esquemas binarios. Así se logran evadir los esquemas teóricos basados en las oposiciones centro y periferia o superior e inferior y otras clases de categorías polarizadas que subrepticiamente se reproducen en tradiciones filosóficas occidentales dominantes. "Habría que desalambrar la teoría y hacerlo con la práctica" (MARCOS, Subcomandante, 2009, p. 33). "Las grandes transformaciones no empiezan arribani con hechos monumentales y épicos, sino con movimientos pequeños en su forma y que aparecen como irrelevantes para el político y analista de arriba..." (Ibidem).

Esta es la propuesta política que le da al zapatismo su color y su sabor y se manifiesta como el meollo de una postura que caracteriza los "nuevos" movimentos sociales. Es lo que Carlos Fuentes, en 1994, llamara la primera "guerrilla postmarxista". Al irrumpir, en la sociedad y en los imaginarios políticos de entonces, a fines de 1993, el zapatismo incluía una Ley Revolucionaria de Mujeres que, en su parquedad, no deja resquicios para los machismos ni androcentrismos institucionales o cotidianos. A través de los años, esta ley ha sido retomada, re-enfatizada, implementada con persistencia para no desviar la atención y el esfuerzo colectivo de esa propuesta zapatista por "otro mundo y otro camino" con las mujeres como eje.

Llegamos así, a finales del 2007, a los testimonios de las 150 mujeres autoridades zapatistas que compartieron sus experiencias en la Garrucha. Nos hablaron de sus 
dificultades, y de ese perpetuo caer y volver a levantarse, para seguir con ese proyecto político tan suyo, tan complejo y tan nuevo. Se ha recorrido un largo camino, ya trazado desde el inicio con la ley revolucionaria de mujeres.

Pero tampoco es la propuesta zapatista una propuesta estrictamente feminista. Es una propuesta política. Las mujeres de "color" en los Estados Unidos habían elaborado terminologías, conceptos y demandas que hacían justicia a la particularidad de su opresión. De ahí emergió la teoría de las intersecciones que ha servido para ampliar, profundizar y distinguir los lineamientos de un feminismo de "color" entre las diásporas culturales dentro de los Estados Unidos. En los movimientos de mujeres indígenas em México y en América latina $\mathrm{y}$, específicamente en el zapatismo, emergieron demandas y prácticas en parte convergentes, pero desde otras coordenadas que no son importaciones ni imitaciones del feminismo urbano del Norte geopolítico - mexicano o internacional ni tampoco restauraciones estrictas de raigambres de cosmo-visión ancestral con la dualidad femenino/masculina. Algunas de sus coordenadas epistémicas son notables por sus particularidades forjadas desde los movimientos de mujeres indígenas. Son productos de una interacción dialógica y creativa entre múltiples influencias, herencias, diferencias, contiendas y reclamos. Así es como se dan adentro del movimento feminista, en permanente creación y recreación. En las comunidades, las mujeres discuten, comparten, reformulan, combinan, cambian o usan estratégicamente los conceptos sociales sobre justicia de género y los términos con los que se habla de ellos. Están además en diálogo permanente con la comunidad internacional y los grupos de mujeres que las apoyan y las visitan.

\section{Aportes epistémicos al feminismo desde los movimientos de mujeres indígenas}

Los principios filosóficos inherentes a la cosmovisión mesoamericana se podrían relacionar con ciertas coordenadas indígenas y feministas (MARCOS, 1994; HOOKS, 1984). Las referencias "teóricas" posibles del movimiento de mujeres indígenas en México y en América latina se nutren de raíces milenarias. Están a la vez en un encuentro con los reclamos feministas, en un flujo y reflujo de discursos, prácticas, uso de términos y de conceptos (MAHMOOD, 2008; BUTLER, 2001) que se entretejen, se cruzan, se confrontan, se 
separan y se re-significan mutuamente, siempre imbricados unos con otros. Esto ocurre tanto en el campo discursivo propio cuanto en el que hacer de la vida cotidiana y en las prácticas. En este tipo de encuentro, el campo privilegiado para su expresión máxima es el de las luchas de las mujeres indígenas zapatistas. Como mujeres, pobres, entretejidas en colectivos, con filiaciones ancestrales mayas y expuestas a las propuestas feministas, ellas reconocen aportes a la justicia de género, pero, a su vez, son el origen de nuevas propuestas. Estas son formas de concebir un feminismo "indígena" que, por extensión, revitalizan aquellas expresiones del feminismo, urbano, teórico, complejo pero desterritorializado y pobre en raigambres culturales.

\section{La encarnación o "corporización" de la "teoría"}

Las formas de concebir lo que podría llamarse su "teoría" feminista se encuentran arraigadas en sus cuerpos y en la materia, materia que forma un conjunto inestable y fluido con la naturaleza y todos los seres que la integran. No es "teoría" de ideas y conceptos abstractos, de lenguaje simbólico y semiótica. Es teoría hablada, vivida, sentida, bailada, olida, tocada. "Queremos agarrar con nuestra mano el derecho [...] pero agarrarlo con fuerza, con las manos, para que no se escape" dirá, palabras más palabras menos, la autoridad de la Junta de Buen Gobierno del Caracol de Morelia Chiapas, en junio de 2009. Estas formas de expresión encarnadas, "corporizadas" son características de los discursos y prácticas de los movimientos de mujeres indígenas (MARCOS, 1995).

En el mundo mesoamericano, en general y maya en particular, el cuerpo no se oponea la mente. No se define como el lugar de los datos biológicos, es decir de lo material e inmanente y tampoco es el límite que marca la frontera entre el ser interno y el mundo exterior. En las tradiciones de las mujeres indígenas organizadas, el cuerpo tiene características muy distintas de las del cuerpo anatómico o biológico moderno. El exterior y el interior no están separados por la barrera hermética de la piel (LÓPEZ, 1984). Entre el afuera y el adentro, existe un intercambio permanente y continuo. Lo material y lo inmaterial, lo exterior y lo interior están en interacción permanente y la piel es constantemente atravesada por flujos de todos tipos. Todo apunta hacia un concepto de corporalidad abierta a los grandes rumbos del cosmos. La ritualidad de las mujeres indígenas 
lo expresa, por ejemplo cuando, al iniciarse uma ceremonia los cuerpos se dirigen alternativamente a cada rumbo o dirección del cosmos. No es un folklore, no se trata de un simple formalismo litúrgico que deberíamos respetar por cortesía. Expresa conceptos profundos de interconexión de los cuerpos y del cosmos, una corporalidad a la vez singular y móvil que incorpora en su núcleo sólidos y fluidos en permanente flujo: aires, vapores, humores y materia. La nueva vida que se gesta en esos cuerpos toma otra dimensión moral y ética que la vida que puede ser objeto de servicios por el sistema biomédico moderno. Esa "nueva vida", hay que saberla vislumbrar.

El entendimiento y la asimilación de estos conceptos de cuerpo pueden enriquecer y dar un "giro decolonial" (LUGONES, 2009; CASTRO, GROSFOGUEL, 2007) al concepto de salud reproductiva y a los esfuerzos feministas por los derechos de las mujeres a la salud. Es teoría y no lo es según como la definimos. No es por supuesto un conjunto de principios abstractos, pero es teoría si la consideramos encarnada y como propia de los universos filosóficos que la sostienen, si se acompaña de fiesta y de danzas, recordando así el lejano origen de la palabra teoría en la palabra griega theoria, que significaba festival.

El cuerpo y el espíritu, la materia y la mente no están concebidos como mutuamente excluyentes. Se viven como un continuum cuyos extremos son polos complementarios, "opuestos", pero que fluyen el uno hacia el otro. Así, no se puede hacer teoría sin cuerpo y sin acción y prácticas. Es en el ejercicio de los derechos que estos se actualizan y existen y constituidos, son un reto a la lógica del Estado neoliberal (SPEED, 2008, p. 37). Reclamando y ejerciendo sus derechos ejercitándolos, desempeñando cargos de autoridad en sus comunidades, así es como las mujeres crean la teoría feminista zapatista. Es "saber hacer" y no "saber sobre", dos formas de construcción de conocimiento, dos epistemès antitéticas (MARCOS, 2010). Cuerpo y espíritu fundidos.

\section{La dualidad como dispositivo perceptual}

Otro referente filosófico para explicar esta conjunción de pares aparentemente opuestos y excluyentes uno del otro lleva a reconocer y re-descubrir la serie de dualidades que estructuran el cosmos mesoamericano/maya. No existe sólo una dualidad de opuestos complementarios (LEÓN PORTILLA, 1983, LÓPEZ, 1984). Más bien coexisten múltiples 
dualidades que se desdoblan, empalman y retroalimentan sin cesar. La dualidad, se podría afirmar, es un dispositivo perceptual mesoamericano.

En el campo político, la dualidad de opuestos fluidos (MARCOS, 2009 a) puede ser una guía para entender como los referentes cosmológicos y filosóficos permiten arreglos, respuestas y soluciones en las prácticas de derechos individuales y colectivos.

Esta dualidad tan reclamada en los documentos, declaraciones y propuestas de las reuniones de mujeres indígenas ha sido, frecuentemente, descalificada por las teóricas/feministas. Instaladas estas en la concepción del sujeto liberal, construido como auto-contenido e individual, están proponiendo la independencia del sujeto "mujer" como ideal de realización personal al margen del colectivo. En las referencias cosmológicas yen las prácticas contemporáneas de las luchas sociales indígenas, no existe el concepto de individuo auto-contenido ni para la mujer ni para el varón. Existe el "nosotros" comunitario (LENKERSDORF, 2005). Así, no es contradictorio, en esos entornos, exigir a la vez los derechos de las mujeres y los derechos colectivos de los pueblos. En esos mundos, como lo manifestaron los discursos de las mujeres zapatistas en la Garrucha (MARCOS, 2009a), los derechos de las mujeres (conceptualizados como derechos individuales) y los derechos colectivos de sus pueblos van juntos y a la par. No se organizan jerárquicamente, no se prioriza uno sobre el otro. No retrasa la lucha el que las mujeres también reclamen sus derechos, al contrario, esta demanda completa la demanda de los pueblos. Simplemente se prosigue enmarcados en esta dualidad de opuestos y complementarios sin priorizar uno sobre el otro. Al respecto, Shannon Speed, entrevistando mujeres de una comunidad de apoyo zapatista, les preguntó si los varones les habían insinuado que ellas deberían esperar para hacer su lucha como mujeres ya que en el momento era necesario un frente común. Obtuvo esta respuesta, después de un largo silencia reflexivo: "Lo opuesto en cierto, es a través de la organización que empezamos a organizarnos, que empezamos a estar conscientes de nuestro derecho como mujeres" (SPEED, 2008, p. 130).

Este dispositivo perceptual mesoamericano constituye un posible referente para el estudio del género en Mesoamérica. Sin embargo, la omnipresencia de éste es tan incluyente que abarca mucho más que el género en el sentido restringido que le dan las académicas y feministas urbanas. Hay que ver más bien el género mesoamericano como la 
metáfora raíz del universo cosmológico, pero aún así, sólo es uno de los posibles arreglos duales y fluidos en este universo.

Volvamos ahora al concepto de intersecciones como definido arriba. Este concepto, originariamente forjado como útil teórico para explicar y orientar las reivindicaciones de las feministas de 'color' en el Norte geopolítico, puede ser extendido a este otro espacio social de lucha que es el de las mujeres indígenas y en el cual se concretiza esta propuesta teórica no sólo discursiva sino práctica. Se habla al respecto de uma conjunción entre derechos de las mujeres y derechos de los pueblos, derechos individuales y derechos colectivos. Estos, podríamos decir, se conciben en intersección. Si así los definimos, entonces no puede existir el uno sin estar incluido y modificado por el otro. La "matriz de dominación" sería entonces el Estado nación neoliberal que interconecta ambos tipos de derechos de las mujeres, los colectivos y los individuales. Aplicando la teoría de las intersecciones, podría interpretarse lo que se vive adentro de las luchas zapatistas, en los caracoles y en sus comunidades de apoyo.

\section{Y la paridad con el varón}

Es importante revisar el impacto del concepto de dualidades fluidas sobre la "lucha de género" (MARCOS, 2007, p. 33). Como es bien sabido, la lucha de las mujeres indígenas busca incorporar a los varones. No se puede concebir como una lucha de mujeres contra o al margen de los hombres. Aunque se expresa como un reclamo y una rebeldía contra situaciones de dominación y sujeción de las mujeres, esa lucha existe a la par, es decir que está subsumida en, y encapsulada por la certeza cosmológica y filosófica de la interdependencia y conjunción con el varón, con la familia, con la comunidad, con el pueblo. Estas características relacionales formadas através de interacciones sociales exigen que los varones participen también en la "liberación" de las mujeres. No existe un imaginario posible sin ellos al lado. Son una en dos y dos en el todo de la interconexión con los seres de la naturaleza y del cosmos.

El concepto mesoamericano de la relación mujer/varón tenía y tiene poderes generadores y protectores (KLEIN, 2001, p. 188). Era y es a la vez un concepto inestable, mutable y fluido. "La cuestión entonces, para la filosofía feminista", dice Teresa de Lauretis, 
"es como repensar la diferencia sexual dentro de la concepción dual del ser" y añade, "un dual absoluto" en el cual ambos, ser mujer y ser hombre, serían primários como "estando ahí desde el principio" (1990, p. 4). No hay anulación del uno por el otro, ni tampoco pretensión de homogeneidad entre ambos y mucho menos una priorización de uno sobre la otra. Parecería que este objetivo y esta búsqueda, esta "complementariedad" forma parte de las referencias cosmológicas ancestrales de los pueblos originarios de las Américas. ¿Cómo inspirar propuestas en la elaboración de una teoría feminista que, sin olvidar los reclamos justos de las mujeres, incorpore estas referencias?

\section{El equilibrio como equidad}

Frecuentemente, las mujeres indígenas organizadas hablan del equilibro y de la armonía como el ideal de la relación entre varones y mujeres. El concepto de equilibrio está presente en sus declaraciones y en los Documentos de la Cumbre de Mujeres Indígenas de América, aparece explícitamente elaborado. Propone “...a todos los pueblos indígenas y movimientos de mujeres indígenas una revisión de patrones culturales con capacidad de autocrítica, con el fin de propiciar unas relaciones de género basadas en elequilibrio" (Memoria, 2003, p. 37). Las búsquedas de igualdad que proponen otros movimientos feministas son interpretadas aquí en términos de búsqueda de equilibrio. "Se entiende así la práctica del enfoque de género como una relación respetuosa... de balance, de equilibrio; lo que en Occidente seria equidad" (Doc. Género, 2002, p. 6) "Los extremos", señala la historiadora mesoamericanista Louise Burkhart, "aunque no tenían que ser evitados completamente, si debían de ser balanceados uno contra el otro" (BURKHART, 1989, p. 130). La fusión-tensión de contrarios en el universo cósmico era la medida y el medio para lograr el equilibrio. Esta referencia epistémica tan presente en toda el área mesoamericana como ideal de bien estar en todos los ámbitos, inspira formas diversas de vivir la justicia de género en las relaciones entre mujeres y varones.

En las raigambres filosóficas brevemente examinadas aquí, se perfila toda otra forma de concebir la "igualdad" social económica y política entre varones y mujeres.

\section{Los movimientos de mujeres mundiales}


El movimiento de mujeres del siglo XXI parece haber tomado la ruta de la apropiación de la ciudadanía plena, colocándose como sujeto del porvenir. Experiencias, visiones y propuestas de quienes tienen en común su decisión de luchar contra el neoliberalismo y fraguar la eu-topía de un mundo diferente. Es un proceso de ruptura con la autorreferencia académica y un procurar confluencias y articulaciones innovadoras. En este sentido, el enfoque de diversidad y pluralismo expresado tan reiteradamente por las mujeres en las reuniones del Foro Social Mundial son una contribución a la diversificación de las perspectivas y con ello, a la viabilidad de la agenda común.

Las mujeres de las bases de los pueblos del mundo han hecho aportaciones muy significativas a las luchas anti-sistémicas. Baste recordar a los colectivos de mujeres en países como la India, con centenas de grupos organizados, Bangladesh, Turquía, Irán, las Filipinas, Brasil, Ecuador y muchos más. Esos movimientos se desdoblan y multiplican cambiando la faz de los movimientos sociales. Abonan desde sus localidades a la construcción de un nuevo mundo. Están generando un proceso de reconceptualizaciones en las que su participación ya no es considerada marginal sino básica. Además, estas conceptualizaciones y prácticas tienen que ver con la definición de un nuevo enfoque a las problemáticas que aquejan a las colectividades humanas, como la militarización, el tráfico de personas, el mercantilismo, las migraciones forzadas y elegidas y las discriminaciones de diverso orden. Están a la orden las conjunciones entre la crítica al neoliberalismo y al patriarcado.

A partir de este entendimiento, se han propuesto nuevas prácticas y estrategias tales como la de procurar alianzas con otros movimientos y de ampliar y abrazar otras problemáticas. Son una contribución para expandir las perspectivas - y no para substituir otras - y lograr que una agenda común sea viable.

Como en todos los cambios, los contenidos de estas reflexiones desde las mujeres, reflejan también una visión crítica de ciertas contradicciones y prácticas patriarcales que se resisten a desaparecer. Especialmente, aquella que pretende relegar las cuestiones de género como un asunto sólo de mujeres, considerándolo, muchas veces, secundario, mientras el movimiento de mujeres está afanándose en pensar y proponer alternativas que atañen a todos y todas. Se han producido análisis y propuestas de orden 
integral. Múltiples movimientos, redes, organizaciones han fortalecido espacios de debate e intercambio con propuestas prácticas y estratégicas. Son las energías del cambio que caracterizan las luchas sociales contemporáneas. Baste referirse aquí solamente a algunos movimientos y redes internacionales - abajo y a la izquierda - como la Marcha Mundial de Mujeres, la Red de Mujeres Transformando la Economía, el Enlace Continental de Mujeres Indígenas, movimientos todos que buscan establecer ejes transversales.

Reconocemos que la presencia de mujeres indígenas en las filas del EZLN contribuyó a legitimar la participación política e insurgente de las mujeres, no sólo en México, sino en el mundo entero. Aun sin que se lo propusieran explícitamente, fue una incitación a recobrar y reafirmar el sentido político amplio de las luchas feministas. Hizo dar un salto a muchas organizaciones hacia los esfuerzos en contra del sistema capitalista. Ayudó - como colectivo de mujeres - a deslindarse del feminismo que sólo ve la subordinación a los varones y deja de lado las múltiples subordinaciones cotidianas y rastreras que nos impone el capitalismo bárbaro y salvaje que destruye no sólo al planeta, sino toda posibilidad de supervivencia humana en armonía y justicia. Es toda una crítica radical al racismo, al patriarcalismo y al capitalismo.

\section{Nota}

Varias pensadoras feministas mexicanas han hecho aportes invaluables a la teoria feminista. Recordando que el feminismo tiene un historial descentralizado y horizontal, y que, como tal, está formado en la pluralidad y recoge posturas múltiples, diversas y a veces contradictorias, es imposible cubrirlas adecuadamente en este espacio. Remito al lector a obras sobre el pensamiento feminista. Entre otras: Las ideas feministas latinoamericanas, por Francesca Gargallo, Ediciones desde Abajo, 2004; y al estudio De lo Privado a lo publico: 30 anos de lucha ciudadana de las mujeres en América Latina, coordinado por Nathalie Leblon y Elizabeth Maier, publicado por Siglo XXI, en coedición con LASA y UNIFEM, en 2006. Invito especialmente a descubrir a una de las precursoras pensadoras y activistas feministas de principios del siglo pasado: Concha Michel.

Todo el andamiaje teórico feminista que emerge desde 1949 con Simone de Beauvoir, con su afirmación de que la mujer no nace sino que se hace, es recogido por Gayle 
Rubin (1975) quien introduce la categoría sexo-género. Ella asigna al sexo biológico (dualidad macho/hembra) unas determinaciones inscritas en la "naturaleza" y en la fisiología humana, mientras que el género es el repertorio de conductas aceptadas socialmente vinculadas a un sexo determinado (dualidad varón/mujer).

En 1982, en El género vernáculo, Iván Illich (2008) contrastó dos tipos de dualidade que tienen ambas que ver con la diferencias entre hombres y mujeres, pero insistiendo en los sentidos radicalmente opuestos de ellas. La primera, el género, vernáculo porque propio de un lugar, es el principio organizador fundamental de casi todas las sociedades premodernas y da su particular color de género no sólo a las mujeres y los hombres, sino también a los tiempos y los espacios, las herramientas y los modos de hablar. El sexo, católico, es decir universal y, hoy, económico, postula un ser humano neutro dotado de caracteres sexuales secundarios. Según Illich, el proceso de modernización es inevitablemente un paso de un tipo de dualidad a otra y el capitalismo es el predomínio del sexo económico.

Judith Butler, a lo largo de toda su obra, ha ido desmontando la categoría binaria míticamente afincada en la fisiología sexual e inevitablemente natural: se es macho o hembra por características genitales. En contraste, todos los repertorios culturales aceptados son de varón o de mujer y conforman el "género". Desafortunadamente, apesar de las múltiples matizaciones y sofisticaciones posteriores en un variado abanico de posturas que se aproximan, lo reformulan, lo desarrollan y aun lo critican, este andamiaje sexogénero ha quedado como el inevitable e invulnerable referente binário de un gran número de teorizaciones feministas. Si empezamos con este referente, descubrimos que, con el oído atento, la escucha cuidadosa e informada, no podemos reducir los discursos sobre el género en las voces de mujeres indígenas a esta fórmula sexo-género de categorías mutuamente excluyentes.

Joan Scott (1990) usa el género como una categoría analítica y sostiene que "el género es un elemento constitutivo de las relaciones sociales basadas en las diferencias que distinguen los sexos" y "una forma primaria de relaciones significantes de poder". El género tiene en la definición de Scott, cuatro aspectos o dimensiones en que es particularmente útil, 1) lo simbólico, 2) la dimensión conceptual normativa, 3) nocionespolíticas, instituciones y organizaciones sociales, 4) la dimensión subjetiva de género (SCOTT, 1990, pp. 44-49). 
La noción de género es introducida por las feministas académicas norteamericanas como categoría analítico-política y, luego, reintroducida en el discurso de los organismos internacionales, especialmente en los de cooperación, como concepto técnico, es decir, supuestamente neutro, a finales de los años 1980 e inicios de los 90, época en que llega con fuerza a América Latina por ejemplo encapsulado en los sloganes "género y desarrollo", "mujer y desarrollo", rápidamente apropiados por el aparato discursivo de los organismos internacionales económicos y políticos del establishment del desarrollo y sus contrapartes del sur.

\section{Referencias}

ALARCÓN, Norma, 1990, The Theoretical Subjects of this Bridge Called y Back and Angloamerican feminism, en Gloria Anzaldua (ed), Making Faces Making Soul: Haciendo Caras, Aunt Lute, San Francisco California.

ANZALDUA, Gloria, 1987, Borderlands/La Frontera: The New Mestiza, San Francisco, California, Spiters, Aunt Lute.

BURKHART, Louise, 1989, The Slippery Earth: Nahua-Christian Moral Dialogue in Sixteenth Century Mexico, Tucson, University of Arizona Press.

BUTLER, Judith, 2001, El genero en disputa: el feminismo y la subversión de la identidad, México, Paidós/ PUEG UNAM.

CASTRO, Gómez, Santiago y GROSFOGUEL, Ramón, 2007, El Giro decolonial, Bogotá, Universidad Javeriana, Instituto Pensar, Universidad centro - IESCO.

COLLINS, Patricia Hill, 1998, La política del pensamiento feminista negro em Marysa Navarro y Catherine Stimpson, (comp.) ¿Qué son los estudios de mujeres? Buenos Aires, Fondo de Cultura Económica.

GARGALLO, Francesaca, 2004, Las ideas feministas latinoamericanas, Bogotá, Ediciones Desde Abajo.

HOOKS, Bell, 1984, Feminist Theory: from Margin to Center, Boston, South End Press.

KLEIN, Cecilia (Ed.), 2001, Gender in Pre-Hispanic America, Washington D.C., Dumbarton aks. 
ILLICH, Iván, 2008, El género vernáculo, en Obras Reunidas, México, Fondo de Cultura Económica.

LAMUS, Doris, 2008, "El lugar político de las mujeres en el movimento egro/afrocolombiano", en Reflexión política, No 20, IEP-UNAB, Colombia.

2009, "Mujeres negras/afrocolombiana en los procesos organizativos en

Colombia: Un aporte al estado del debate", en Reflexión política, No 21, IEPUNAB, Colombia.

LAURETIS, Teresa de, 1990, "The Practice of Sexual Difference and Feminist thought in Italy", Introduction, en Sexual Difference, A Theory of Social Symbolic Practice.

LENKERSDORF, Carlos, 2005, Filosofar en clave tojolabal, México, Porrúa.

LEÓN, Irene, 2005, Mujeres en resistencia: experiencias, visiones y propuestas, Quito, ALAI, 2a edición, The Milan Women's Bookstore Collective, Bloomington, Indiana University Press, (Ed.).

LEÓN, Portilla Miguel, 1983, La filosofía náhuatl, estudiada en sus fuentes, México, UNAM.

LÓPEZ, Austin A., 1984, Cuerpo humano e ideología, México, UNAM/ IIA.

LORDE, Audre, 1984, Sister Outsider, Trumansburg, N.Y., Crossing Press.

LUGONES, Maria, 2003, Pilgrimages/ Peregrinajes: Theorizing Coalition Against Multiple Oppressions, Boulder New York, Rowman and Littlefield Publishers.

LUGONES, María, 2009, "Colonialidad y género: hacia un feminismo decolonial” BINGHAMPTON, Ms de trabajo.

MAHMOOD, Saba, 2008, "Teoría feminista y el agente social dócil: algunas reflexiones sobre el renacimiento islámico en Egipto”, en L. Suárez y A.Hernández, Descolonizando el eminismo, Madrid, Cátedra.

MARCOS, Sub-comandante, 2009, "Ni el centro ni la periferia, parte $\mathrm{V}$, oler el negro, El calendario y la geografía del miedo" en Planeta tierra y movimentos antisistémicos, San Cristóbal de las Casas, CIDECI/ Unitierra.

MARCOS, Sub-comandante, 2009, “Parte I, Arriba, Pensar el blanco, La geografía y el calendario de la teoría", en Planeta tierra y movimientos antisistémicos, SanCristóbal de las Casas, $\mathrm{CIDECl} /$ Unitierra.

MARCOS, Sylvia, 2010, Cruzando fronteras: mujeres indígenas y feminismos abajo ya la izquierda. San Cristóbal de las Casas, CIDECI/ Unitierra. 
2010. "La insurgencia de los saberes avasallados" Ponencia, Seminario Internacional, San Cristóbal de las Casas, CIDECI. Enero 2.

2009 a. "Otro mundo, otro camino, feminista" Ponencia EZLN, Primer festival de la digna rabia, San Cristóbal de las Casas/ CIDECI.

2009 b. "Mesoamerican Women Indigenous Spirituality" en Journal of Feminist Studies in Religion, Vol. 25, No 2, Indiana, Indiana UniversityPress.

2000. "Género, clase y etnicidad" en Equis. No 23 Marzo, México.

2000. Comprendiendo el género en su contexto cultural. Conferencia magistral, Seminario Género e Interculturalidad, CREFAL, Pátzcuaro, Junio.

1994. "Género y reivindicaciones indígenas" La Doble Jornada, no.5,

Diciembre.

1995. "Pensamiento mesoamericano y categorías de género: un reto epistemológico", en La palabra y el hombre, Xalapa, Universidad Veracruzana, no.

6.20

1977. Rituales de interacción femenino-masculino en México, em Juana A. Alegría, (ed) Mujer Viento y Ventura, México: Diana.

MIGNOLO, Walter. Historias locales/Diseños globales, colonialidad, conocimiento subalterno y pensamiento fronterizo, Madrid, Akal.2003.

Primera Cumbre de Mujeres Indígenas de América, 2003, Memoria México, Fundación Rigoberta Menchú.

Primera Cumbre de Mujeres Indígenas de América, Doc. Base de discusión: Género desde la visión de las mujeres indígenas. Universidad de las Regiones Autónomasde la Costa Caribe Nicaragüense URACCÁN, Centro de Estudios e Información de la Mujer Multiétnica. Ms.

ROWBOTHAM, Sheyla, 1980, La mujer ignorada por la historia, Madrid, Debate.

RUBIN, Gayle, 1975, "The Traffic in Women: Notes on the "Political Economy" of Sex" en Rayna R. Reiter, (Ed.), Towards an Anthropology of Women, New York and London, Monthly Review.

SCOTT, Joan, 1990, "El género una categoría útil para el análisis histórico", en James Amelang y Mary Nash (eds), Historia y género, Valencia, Alfons el Magnanim, Espania.

TRINH, Min-ha, 1989, Woman, Native, Other: Writing Postcoloniality and Feminism, Indiana, Indiana Unviersity Press. 
SPEED, Shannon, 2008, Rights in Rebellion. Indigenous Struggle and Human Rights in Chiapas. Stanford, Stanford University Press.

RECEBIDO EM 20 DE ABRIL DE 2013.

APROVADO EM 01 DE JUNHO DE 2013. 